\title{
Arazi Kullanımdaki Zamansal Değişimin Kıyı Kenar Çizgisi ve Mülkiyet Açısından Değerlendirilmesi: Erzin İlçesi Örneği
}

\author{
Faz1l Nacar ${ }^{1 *}$ \\ ${ }^{1}$ Osmaniye Korkut Ata Üniversitesi, Mühendislik Fakültesi, Harita Bölümü, Osmaniye, Türkiye (ORCID: 0000-0000-0000-0000)
}

(International Congress on Human-Computer Interaction, Optimization and Robotic Applications (HORA) 2021 - 11-13 June 2021)

(DOI: $10.31590 /$ ejosat.956465)

ATIF/REFERENCE: Nacar, F. (2020). Arazi Kullanımdaki Zamansal Değişimin Kıyı Kenar Çizgisi ve Mülkiyet Açısından Değerlendirilmesi: Erzin İlçesi Örneği. Avrupa Bilim ve Teknoloji Dergisi, (26), 315-324.

\section{$\ddot{O} z$}

Kıyılar sahip oldukları doğal kaynaklar ve insanlar tarafından yerleşme, ulaşım, turizm ve ticaret gibi sektörlerin yoğun olarak yapıldığı mekanlardır. Bu nedenle kıyılar tahrip olmaya ve değişime uğramaya devam etmektedir. Ülkemizde kıyıların korunması ve kullanılması ile ilgili birçok mevzuat bulunmaktadır.

Kıyı kenar çizgisinin geçirilmesi ve kıyı planlaması önemli bir işlemdir. Kıyıdaki değişimin tespiti konusunda farklı zamanlarda üretilmiş hava fotoğrafları ve uydu görüntüleri sıklıkla kullanılmaktadır. Bu sayede kıyıdaki tahribatlar kolaylıkla ortaya çıkmaktadır. Koruma kullanma dengesi ve yapılması gereken denetim ve işlemler konusunda resmî kurumlara ışık tutmaktadır.

Bu çalı̧̧mada Hatay ili Erzin ve Dörtyol ilçelerinin doğu Akdeniz sahil bölgesindeki arazi kullanımlarındaki zamansal değişim farklı tarihlerde üretilmiş ortofoto ve fotogrametrik haritalar yardımıyla karşılaştırmalı olarak incelenmiş ve kıyı kenar çizgisi, arazi planlaması ve mülkiyet üzerindeki etkisi araştırılarak değerlendirilmiştir.

Çalışmanın amacı Doğu Akdeniz bölgesinde Erzin ve Dörtyol ilçeleri sahil bölgesinde arazi kullanımındaki zamansal değişimi tespit etmek, değişim sürecinin kıyı kenar çizgisi, arazi planlaması ve mülkiyet üzerindeki etkisini araştırmaktır. Kurumsal olarak Kadastro Müdürlüğü, belediyeler, Çevre ve Şehircilik müdürlüğü gibi kurumlara araştırma sonuçları konusunda bilgiler sunulacak ve araştırma sonucunun hayata geçirilmesi konusunda önerilerde bulunulacaktır.

Çalışmada kıyı kenar çizgisi çalışmaları başlamadan önce ve sonraki arazi kullanımındaki zamansal değişimle birlikte mülkiyet durumu ve arazi planlaması irdelenmiş, bu bölgedeki hak sahipliği ve ihlaller ortaya çıkarılmıştır. 1975 ve 2011 tarihli hava fotoğrafları ile 2015 tarihli ortofoto kullanılarak kadastro haritası ve kıyı kenar çizgisi noktaları karşılaştırılarak mülkiyet ve planlama konusunda analiz yapılmıştır. Ayrıca bölgedeki kıyı kenar çizgisine yapılan ihlaller mahalle ve parsel bazlı olarak ortaya konmuştur. $\mathrm{Bu}$ sayede kurumlar, denetim ve koruma konusunda gerekli işlemleri yapacaklardır.

Anahtar Kelimeler: Kıyı Kenar, Ortofoto, Zamansal Değişim, Arazi Planlaması, Mülkiyet.

\section{Evaluation of Temporal Change in Land Use in Terms of Coastal Line and Ownership: The Case of Erzin District}

\begin{abstract}
Coasts are places where sectors such as settlement, transportation, tourism and trade are intensely carried out by their natural resources and people. Therefore, the coasts continue to be destroyed and changed. In our country, there are many legislation related to the protection and use of the coasts.

Passing the coastal line and coastal planning is an important process. Aerial photographs and satellite images produced at different times are frequently used to detect the change on the shore. Thus, the damage on the shore can be easily seen.

In this study, the temporal change in land use in the eastern Mediterranean coastal region of Erzin and Dörtyol districts of Hatay province was analyzed comparatively with the help of orthophoto and photogrammetric maps produced at different dates, and the effects on the coastal edge line, land planning and property were evaluated.

The aim of the study is to determine the temporal change in land use in the coastal region of Erzin and Dörtyol districts in the Eastern Mediterranean region, and to investigate the effect of the change process on the coastal edge line, land planning and property.
\end{abstract}

\footnotetext{
* Fazıl Nacar: Osmaniye Korkut Ata Üniversitesi, Mühendislik Fakültesi, Harita Bölümü, Osmaniye, Türkiye, ORCID: 0000-0001-8434-5038,
} 
Institutionally, institutions such as the Cadastre Directorate, municipalities, the Directorate of Environment and Urbanization will be provided with information on the results of the research and recommendations will be made on the implementation of the research result.

In the study, ownership status and land planning were examined before and after the start of the coastal line studies, together with the temporal change in land use, and rights ownership and violations in this region were revealed. By using aerial photographs dated 1975 and 2011 and orthophoto dated 2015, cadastral map and shore edge line points were compared and an analysis was made on ownership and planning. In addition, violations of the coastal line in the region have been revealed on the basis of neighborhoods and parcels. In this way, the institutions will take the necessary actions for inspection and protection.

Keywords: Coastal Edge, Orthophoto, Temporal Change, Land Planning, Property.

\section{Giriș}

Dünyada ilk yaşam aktivitelerinin görüldüğü ve insanların medeniyetler kurarak hayatını sürdürdüğü alanlar, su kaynaklarının bol olduğu bölgeler olmuştur. Günümüzde dünya nüfusunun $2 / 3$ ' ünün yaşamını sürdürdüğü kıyı bölgelerinin önemi sürekli olarak artmaktadır. (Aykut vd., 2005). Türkiye nüfusunun yaklaşık yüzde altmış beşi kıyı bölgelerinde yaşamaktadır. (URL.2) Türkiye İstatistik Kurumu, 2019-a). Konut, sanayi, ticaret ve turizm sektörlerinin gelişme etkisine yoğun olarak uğrayan kıyı bölgelerinde yığılmalar olmaktadır. (Öztürk D.,2013) Bu etki nedeniyle kıyılarda doğal ya da yapay değişimler görülmektedir. Kıyı bölgelerinin önemi bakımından iyi korunması ve yönetilmesi gerekmektedir. Türkiye kıyı kanunlarına göre; kıyı çizgisi, deniz, göl ve nehirlerde, taşkın durumları haricinde, hava olaylarına göre değişen, suyun kara parçasına değdiği noktaların birleşmesinden oluşan tabi hattır. (URL.1). Kıyı çizgisinin belirlenmesi ve izlenmesi için çeşitli yöntemler kullanılmaktadır (Gens R., (2010), Li R., Di K., and Ma R., (2001).

Türkiye'deki deniz ve kıyı mevzuatı incelendiğinde; denizlerin ve kıyıların Devlet kontrolünde olduğu, kıyılarda özel mülkiyet bulunmadığı ve bu alanların tescil edilemediği belirtilmektedir. Tersine kıyıların çeşitliliği, önemi hızla arttığı, yenilenemez ve tekrar üretilemez oldukları için, bu değişen alanları kontrol etmek ve bu çeşitli faaliyet ve talepleri sınırlamak ve araştırmak için kayıt ihtiyaçları ortaya çıkmaktadır. (Çay, T and Nacar, F. 2016).

Geçmişten günümüze insanların yerleşerek uygarlıklar kurduğu, uluslararası kültür ve ticaret alışveriş alanları olan kıyı bölgeleri bugünde konut, sanayi, enerji, gemi yapımı, turizm, ticaret, ulaşım ve balıkçılık gibi sektörlerin konumlanmak için rekabet ettiği alanlardır. Kıyılara yerleşme konusundaki bu yarış uyumsuz kullanım biçimlerine kıyıdaki doğal kaynakların ve ekolojik dengenin bozulmasına sebep olan plansız yerleşmeleri artırmaktadır. $\mathrm{Bu}$ plansız yerleşmeler nedeniyle sosyal, ekonomik, çevresel ve mekânsal sorunlar oluşmaktadır. (URL.4).

Hem dünyada hem de ülkemizde kıyı-kıyı kenar çizgisi ve kıyı çizgisi değişiminin tespit edilmesi problemleri bulunmaktadır. Kıyı kenar çizgisinin belirlenmesinde, yersel ve hava fotogrametrisi, LIDAR sistemleri ve klasik ölçme teknikleri kullanılmaktadır. Uzaktan algılama yönteminde kullanılan uyduların özelliklerine göre hassasiyeti ve maliyeti değişen uydu görüntülerinin çok tercih edildiği gözlenmiştir (Ünel vd., 2019). Landsat görüntüleri analiz edilerek kıyı bölgelerinde ve kritik arazilerde değişiklikler belirlenmiştir. Hava fotoğrafları ve uydu görüntüleri GİS kullanılarak analiz edilmiştir. (Supriyono,2018). Kazakistan'da Alakol Gölü boyunca kıyı şeridi değişimlerindeki geçmiş eğilimleri araştırılmış ve uydu görüntüleri Landsat-5 TM, 7 ETM +, 8 OLI ve Sentinel-2A olmak üzere uzaktan algilama verilerini kullanarak değişim oranını tahmin edilmiştir. (Velayev, A., and other.,2019) Bangladeş'in Hatiya Adası'nda 1989'dan 2010'a kadar kıyı şeridi değişikliklerini izlemek için entegre uzaktan algılama ve coğrafi bilgi sistemi (GIS) tekniklerini kullanılmıştır. Hatiya Adası kıyı bölgesinde belirtilen dönemde meydana gelen zamansal değişiklikleri ölçmek için Thematic Mapper (TM) ve Enhanced Thematic Mapper (ETM) uydu görüntüleri kullanılmıştır. ((Ghosh, M. K., Kumar, L., and other 2015). Güneybatı Tayvan'daki uzun vadeli kıyı değişimine ilişkin bir vaka çalışması veri kümesinin analizine dayanan bir yönetim çerçevesinin ana hatlarını çizmiştir. 1974 ile 2015 yılları arasında uydudan türetilen bir dizi görüntü değerlendirilmiştir. Ulusal çaptaki en iyi kıyı çevre koruma planı, kentleşmenin ertelenmesini ve kullanılmayan kıyı sulak alanlarının korunmasını önerilmiştir. (Chang, Y. And other 2018). Hava fotoğrafları ve uydu görüntüleri temel alınarak, 1962-2005 yılları arasındaki periyotta, Kepez Deltasındaki arazi kullanım özellikleri ve kıyı çizgisi değişimlerini ortaya koyulmuştur. (Akbulak, C and other .2008). Sakarya Karasu nehrinin kiy1 şeridindeki değişimi değişik tarihli uydu görüntüleriyle tespit etmişlerdir (Aydın .M ve Uysal.M 2013).

Kıyı ve sahil şeritlerinde doğal dengenin korunması, mülkiyet analizlerinin yapılması ve bu çalışmalarla ilgili en etkin planlama kararlarını verebilmek için bölgenin uydu görüntüsü veya sayısal verileri kullanılarak Coğrafi Bilgi Sistemi ile Kıyı Alanı Yönetim Bilgi Sistemleri gerçekleştirilerek öncelikle mevcut durum ortaya konulmuștur. Daha sonra bu sistem yardımıyla Kıyı Alanlarının takip, denetim ve korunması sağlanması önerilmiştir. (Sesli F.A ve ark 2002.)

Yapılan çalışmayla Doğu Akdeniz de Hatay ili Erzin İlçesi sınırlarında kalan ve sahil şeridini oluşturan Turunçlu (kadastro yenilemesi sonrası Yukarıburnaz, Aşağıburnaz ve Turunçlu olarak üç mahalleye ayrıldı ), Yeşilkent (sahil bölgesi kadastro yenileme çalışması sonrası Aşağıburnaz Mahallesi oldu) ve Dörtyol İlçesi Yeniyurt , mahallelerinin kıyı bölgesinde arazi kullanımındaki zamansal değişim hava fotoğrafları ve ortofoto yardımıyla tespit edilmiş, ,Kıyı kenar çizgisi koordinatları , kadastro haritalarıyla çakıştırılmıştır. Kıyı kenar çizgisi içerisinde (ihlal eden) kalan parseller mahalle bazında belirlenmiş ayrıca ihlal miktarları alansal olarak hesaplanmıştır. Ayrıca arazi kullanım planlaması incelenmiş ve kıyı bölgesindeki plan revizyonları ve kıyı bölgesine etkileri değerlendirilmiştir.

$\mathrm{Bu}$ çalışmada kıyı kenar çizgisi çalışmaları başlamadan önce ve sonraki arazi kullanımındaki zamansal değişimle birlikte mülkiyet durumu da irdelenmiş, bu bölgedeki hak sahipliği ve ihlaller ortaya çıkarılmıştır. Harita genel müdürlüğünden alınan 1975 ve 2011 tarihli hava fotoğrafları ile Hatay Büyükşehir Belediyesinden temin edilen 2015 tarihli ortofoto kullanılarak kadastro haritası ve kıyı kenar çizgisi noktaları karşılaştırılarak mülkiyet konusunda analiz yapılmıştır. Ayrıca bölgedeki kıyı kenar çizgisine yapılan ihlaller mahalle ve parsel bazlı olarak ortaya konmuştur. 


\section{Materyal ve Metot}

\subsection{Kıyı Mevzuatı}

Kıyı kanunu göre;

Tanımlar;

Deniz, tabii ve suni göl ve akarsularda, taşkın durumları dışında, suyun karaya değdiği noktaların birleşmesinden Kıyı çizgisi oluşmaktadır. Kıyı çizgisinden sonraki kara yönünde su hareketlerinin oluşturulduğu kumluk, çakıllık, kayalık, taşlık, sazlık, bataklık ve benzeri alanların doğal sınırı kıyı kenar çizgisini oluşturmaktadır. Kıyı çizgisi ve kıyı kenar çizgisi arasındaki alana kıyı denmektedir. Kıyı kenar çizgisinden itibaren kara yönünde yatay olarak en az 100 metre genişliğindeki alan sahil şeridi olarak tanımlanmaktadır.

\section{Kıyılar ile İlgili Genel Esaslar;}

Kıyılar, Devletin hüküm ve tasarrufu altında, herkesin eşit ve serbest olarak yararlanmasına açıtır, bu alanlardan yararlanmada öncelik kamu yararına göre düzenlenir. $\mathrm{Bu}$ alanlarda planlama ve uygulama yapılabilmesi için kıyı kenar çizgisinin tespiti zorunludur., Talep tarihini takip eden üç ay içinde kıyı kenar çizgisinin tespiti zorunludur. Sahil şeritlerinde yapılacak yapılar kıyı kenar çizgisine en fazla 50 metre yaklaşabilir. Kıyı kenar çizgisi, valiliklerce, kamu görevlilerinden oluşturulacak, jeoloji mühendisi, jeolog veya jeomorfolog, harita ve kadastro mühendisi, ziraat mühendisi, mimar ve şehir plancısı, inşaat mühendisinden oluşan en az 5 kişilik bir komisyonca tespit edilir. Komisyonca tespit edilen kıyı kenar çizgisi valiliğin uygun görüşü ve Çevre ve Şehircilik Bakanlığının onayıyla yürürlüğe girer.

Uygulama imar planı bulunmayan alanlardaki sahil şeritlerinde, 4'üncü maddede belirtilen mesafeler içinde hiçbir yap1 ve tesis yapılamaz. Uygulama imar planı bulunan yerlerde duvar, çit, parmaklık, tel örgü, hendek, kazık ve benzeri engeller oluşturulamaz. Moloz, toprak, cüruf, çöp gibi kirletici ve çevreyi bozucu etkisi olan atık ve artıklar dökülemez, kazı yapılamaz. Ancak bu alanlarda; uygulama imar planı kararıyla altı ve yedinci maddede belirtilen yap1 ve tesislerle birlikte toplum yararına açık olmak şartıyla konaklama hariç günü birlik turizm yap1 ve tesisleri yapılabilir.

\section{Bütünleşik Kıyı Planları;}

"Kıyıları, etkileşim alanı ile birlikte tüm sektörel faaliyet ve planları, sosyal ve ekonomik konuları da içerecek şekilde bütünleşik bir yaklaşımla ele alan, koruma ve kullanma dengesini sağlayacak biçimde mekânsal hedef, strateji ve eylem önerilerini ve yönetim planını kapsayan, $1 / 25.000$ veya $1 / 50.000$ ölçekte şematik ve grafik planlama diline uygun, plan paftası ve planlama raporu ile bütün olarak stratejik planlama yaklaşımı çerçevesinde ilgili kurum ve kuruluşlar ile işbirliği içinde hazırlanan plandır."(URL .4).

\subsection{Hatay İli Erzin ve Dörtyol İlçeleri Hakkında}

Hatay ili ülkemizin güneyinde doğu Akdeniz bölgesinde İskenderun körfezinde yer almaktadır. Kuzeyinde Adana, Osmaniye, Gaziantep ileri, güney ve doğusunda Suriye, kuzeydoğusunda Gaziantep, kuzey ve kuzey batısında Osmaniye ve Adana, batısında ise Akdeniz ile çevrilidir. İlin Doğu Akdeniz'e 185 km kıyı şeridi mevcut olup yüzölçümü 5.403 $\mathrm{km}^{2}$ 'dir. (URL.3).

Erzin ve Dörtyol, Hatay’ın bir ilçeleridir. Erzin Adana, Osmaniye, Dörtyol ve İskenderun Körfezi ile çevrilidir. Erzin İlçesi'nin Doğu Akdeniz'e 10 km kıyısı mevcuttur. Erzin İlçesi Kıyı bölgesinde Aşağıburnaz, Yukarıburnaz, Turunçlu, Yeşilkent mahalleleri bulunmaktadır. (URL.3,2020). Dörtyol İlçesi Doğu Torosların uzantısı olan Amanos Dağları ile Akdeniz'in İskenderun Körfezi arasında Kuzey-Güney doğrultusunda uzanan Dörtyol ve Payas Alüviyal ovalarından meydana gelmiştir. Kuzeyinde Erzin, Güneyinde ise İskenderun İlçesi bulunmaktadır. (URL.5) Dörtyol İlçesi kıyı uzunluğu yaklaşık 18 km olup, kıyı bölgesinde Yeniyurt, Yeşilköy, Çaylı, Numuneevler ve Özerli mahalleleri bulunmaktadır.

\section{3. Çalışma Alanı Hakkında}

\subsection{1. Çalışma alanının Kadastral İncelemesi}

Hatay ili Erzin İlçesi’nin Doğu Akdeniz’le kıyı ilişkisi olan Turunçlu (kadastro yenilemesi sonrası Yukarıburnaz, Aşağıburnaz ve Turunçlu olarak üç mahalleye ayrıldı), Yeşilkent (sahil bölgesi kadastro yenileme çalışması sonrası Aşağıburnaz Mahallesi oldu) ve Dörtyol İlçesi Yeniyurt mahalleri bulunmaktadir.

Çalışma alanına ait kadastral paftalar Hatay Kadastro Müdürlüğünden ve tapu kayıtları da Erzin ve Dörtyol Tapu Müdürlüklerinden temin edilmiştir.

Turunçlu, Yeniyurt ve Yeşilkent mahallelerinin ilk tesis kadastroları 1964 yılında yapılmış olup, kadastro yenileme çalışmaları günceldir. Turunçlu Mahallesi kadastro yenileme çalışması 08.10.2020 tarihinde ve Yeşilkent Mahallesi yenileme kadastrosu da 12.10.2020 tarihinde kesinleşmiştir.

Erzin İlçesi kıyı şeridinde kalan Turunçlu (kadastro yenilemesi sonrası Yukarıburnaz, Aşağıburnaz ve Turunçlu olarak üç mahalleye ayrıldı) Yeşilkent (sahil bölgesi kadastro yenileme çalışması sonrası Aşağıburnaz Mahallesi oldu) ve Dörtyol İlçesi Yeniyurt mahallerinin Kadastro haritaları birleşik olarak gözükmektedir. Söz konusu mahallelerde kadastro yenileme çalışmaları yapılmış ve kadastral parseller ülke koordinat sistemi ile sayısal olarak oluşturulmuştur.

\subsubsection{Kıyı Kenar Çizgisi Bakımından İnceleme}

Kıyı kenar çizgisi haritaları Hatay Çevre ve şehircilik İl Müdürlüğünden temin edilmiştir. Çalışma bölgemiz Erzin İlçesi'nin Doğu Akdeniz'e 12630 metre kıyısı olup bu alanda Aşağıburnaz, Yukarıburnaz, Turunçlu, Yeşilkent ve Yeniyurt (Dörtyol'a bağlı kısmen) mahalleleri bulunmaktadır. 


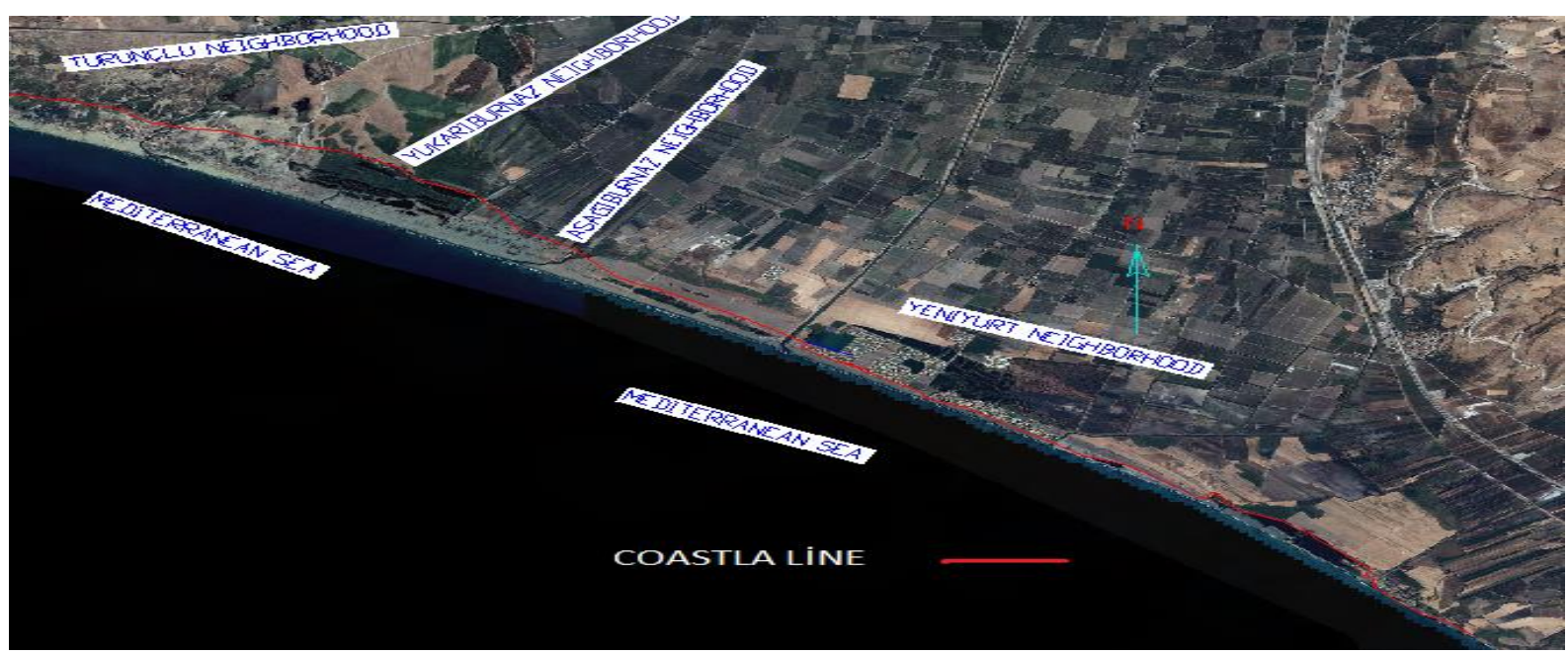

Şekil 1 Erzin İlçesi kıyı kenar çizgisi noktaları

Şekil 1 de Erzin İlçesi kıyı kenar noktaları, Hatay çevre şehircilik il müdürlüğünden temin edilmiştir. Kıyı kenar çizgisi Hatay Valiliği'nce oluşturulan komisyonca tespit edilen ve Valilikçe uygun görülen kıyı kenar çizgisi 3621 sayılı Kıyı Kanununun 9.maddesi uyarınca 04.09.2000'de Bayındırlık ve
İskân Bakanlığı Teknik Araştırma ve Uygulama Genel Müdürlüğ̈̈’nce onaylanmıştır. Onaylanan kıyı kenar çizgisi noktaları kadastro yenileme çalışmalarında dikkate alınarak kadastro haritasıyla ilişkilendirilmiştir.

Tablo 1. Çalışma alanı kıyı kenar çizgisi tespitleri

\begin{tabular}{c|c|c|c|c|c}
\hline \multirow{2}{*}{ İlçesi } & Mahalle & $\begin{array}{c}\text { Kıyı } \\
\text { uzunluğu(metre } \\
\text { ) }\end{array}$ & $\begin{array}{c}\text { KKÇ tespiti } \\
\text { yapılmış parsel } \\
\text { sayısı }\end{array}$ & $\begin{array}{c}\text { Gerçekleşme } \\
\text { oranı (\%) }\end{array}$ \\
\hline Dörtyol & & Yeniyurt & 5500 & 83 & 100 \\
\hline Erzin & $\begin{array}{c}\text { Turunçlu, } \\
\text { Aşağıburnaz, } \\
\text { Yukarıburnaz }\end{array}$ & 5880 & 5 & 100 \\
\hline Erzin & $\begin{array}{c}\text { Yeşilkent } \\
\text { (Aşağıburnaz) }\end{array}$ & 1250 & 1 & 100 \\
\hline
\end{tabular}

Tabblo 1'den de anlaşılacağı üzere Yeşilyurt Mahallesi kıyın uzunluğu $5500 \mathrm{~m}$ ve 83 kadastro parseli Kıyı kenar çizgisiyle ilişkilidir. Turunçlu, (Aşağıburnaz, Yukarıburnaz) Mahallesi $5580 \mathrm{~m}$ kıyı uzunluğuna sahip ve 5 kadastro parseliyle ilişkilidir. Yeşilkent (Aşağıburnaz) Mahallesi en kısa kıyı uzunluğuna sahip ve $1250 \mathrm{~m}$ kıyı uzunluğunda bir kadastro parseliyle ilişkilidir.

\subsubsection{Zamansal Değişim Açısından İnceleme}

Çalışma bölgemiz olan Hatay ili Erzin İlçesi'nin Doğu Akdeniz kıyılarındaki Turunçlu, Yukarıburnaz, Aşağıburnaz (Yeşilkent) ve Yeniyurt mahallelerine ait eski ve yeni tarihli hava fotoğrafları ve ortofotolar Harita Genel müdürlüğünden ve Hatay Büyükşehir belediyesinden temin edilmiştir. Hava fotoğrafları 1975 ve 2011 tarihinde üretilmiştir. Ortofoto ise 2015 tarihinde üretilmiştir. Bu veriler ışığında 30 yıllık bir zaman sürecindeki kıyı bölgesinin değişimi analiz edilmiştir Erzin belediyesinden alınan Hatay ili Çevre düzeni planı Antakya O36 paftası 1/100.000 ölçeğinde olup çalışma bölgemizi de içine alan kıyı bölgesindeki arazi kullanım planlamasını ortaya koymaktadır. Arazi kullanım planlamasındaki değişim kıyı bölgesindeki değişimin en önemli sebeplerinden biridir.

\subsection{Dijital (Sayısal) Fotogrametri}

Sayısal hava kümesinin kullanımıyla fotogrametri üretim süreci değişmiştir. Analog kameradaki kavramlar değişmiş, maliyet azalmış otomasyonda fayda sağlanmıştır. Resim ölçeği yerine yer örnekleme aralığına bırakmıştır. Film ve banyo işlemleri ortadan kalkmış ve yerine bilgisayarda hem görüntülerin işlemi süreci ortaya çıkmıştır (Kiracı et al., 2010). Fotogrametri olarak sayısal yükseklik modeli, ortofoto harita ve vektör harita üretilebilmektedir.

\section{Uygulama}

\subsection{Kıyı Bölgesindeki Zamansal Değişimin İrdelenmesi}

Yaptığımız çalışmada Harita genel müdürlüğünden elde ettiğgimiz kıyı bölgesi hava fotoğrafları üzerinde geometrik düzeltme yapılarak, kıyı kenar çizgisi koordinatlarıyla çakıştırılmıştır. 1975 tarihli hava fotoğrafında kıyı bölgesindeki durumla (yapılaşma ve arazi kullanım durumu) 2011 tarihli hava fotoğrafindaki durum ve 2015 tarihli ortofotodaki durum karşılaş̧ırılmıştır.

Turunçlu Mahallesi'nin kıyı bölgesine ait Harita Genel müdürlüğünden alınan 1975 tarihli hava fotoğrafindan anlaşılacağı üzere yapı bulunmamaktadır. 


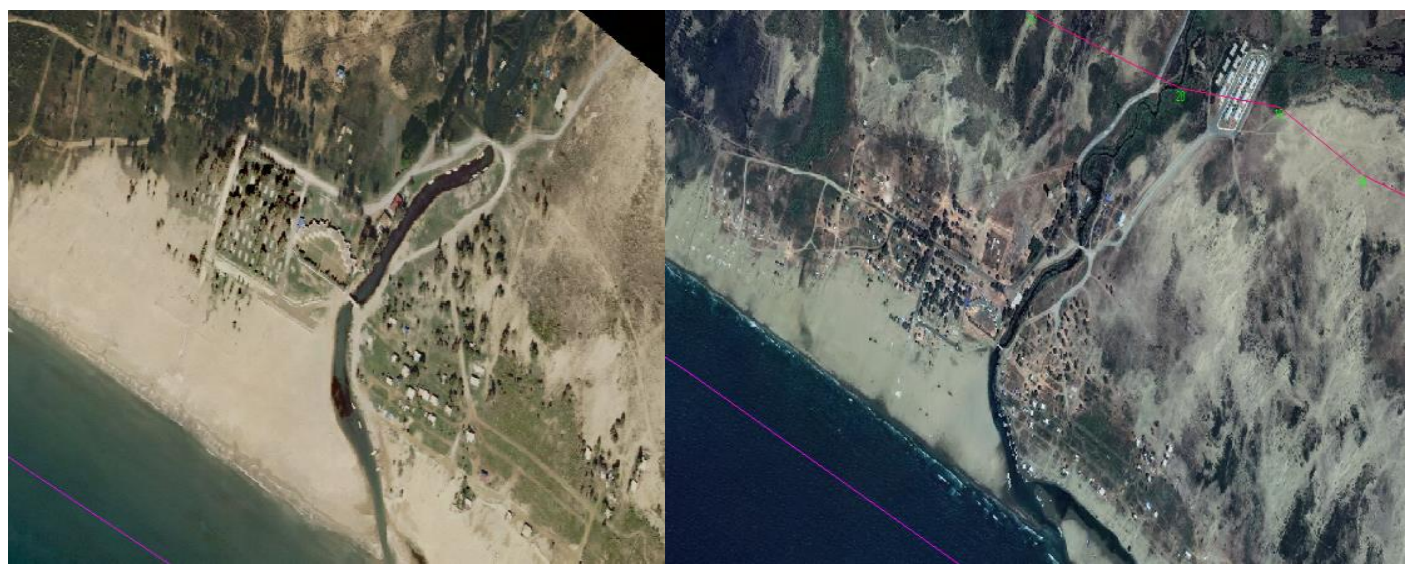

a)

b)

Şekil 2. a) 2011 tarihli hava fotoğrafindaki b)2015 ortofotodaki görünüşü

Şekil 2'dan anlaşılacağı üzere 2011 yılındaki hava fotoğrafında kıyı bölgesinde yapılaşmalar gözükmektedir. Şekil 2. b) deki 2015 tarihli ortofotoya göre ise yapıların yıkıldı̆̆ 1 (Hatay büyükşehir belediyesi tarafından) gözükmektedir.

Aşağıburnaz Mahallesi 1975 ve 2011 tarihli hava fotoğrafındaki görüntüye ve 2015 tarihli ortofotoya göre k1yı

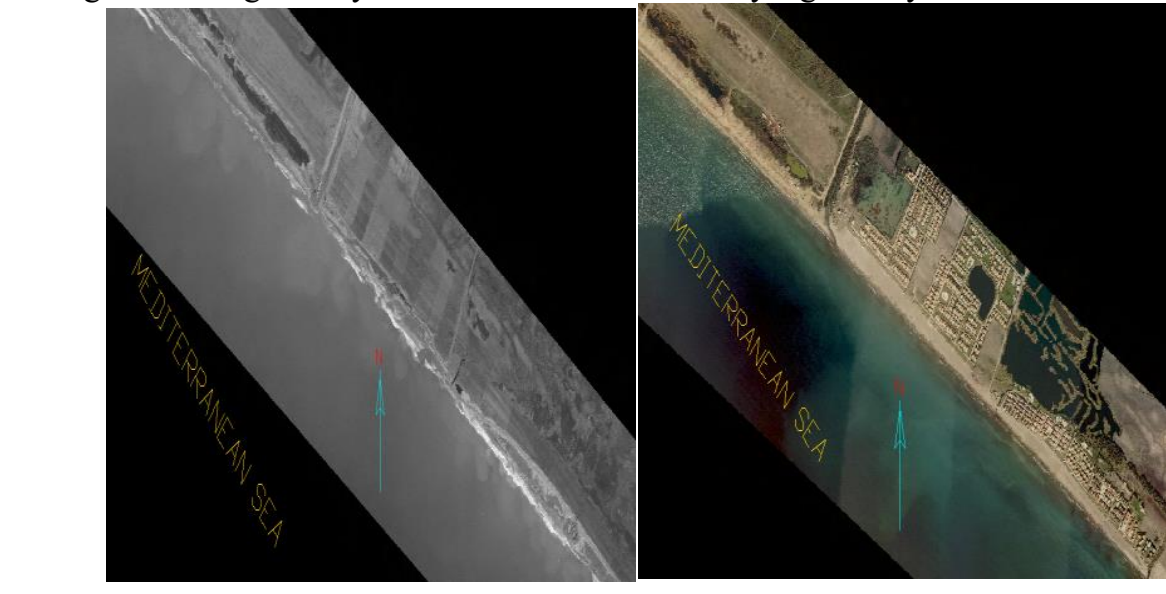

a) b) uzunluğunun (1250m) diğer mahallelere göre kısa olması ve tek parsellik kamu mülkiyetinde bir parsel ve tescil harici alan oluşu yapılaşmayı engellemiştir. $\mathrm{Bu}$ mahalle kıyısında herhangi bir yapılaşma söz konusu değildir.

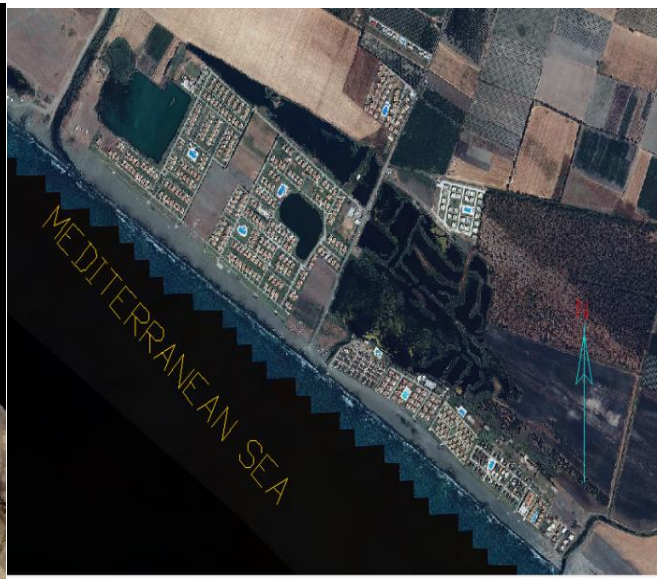

c)

Şekil 3. Yeniyurt Mahallesi a) 1975 tarihli hava fotoğrafindaki görünüşü, b) Yeniyurt Mahallesi 2011 tarihli hava fotoğrafindaki görünüşü c) 2015 tarihli ortofoto

Şekil 3'den anlaşılacağı üzere 1975 tarihinde Yeniyurt kıyı bölgesinde herhangi bir yapılaşma yok iken 2011 ve 2015 yıllarında kıyı bölgesinde birçok yapı yapılmıștır.2011 yılında ki hava fotoğrafında sadece kıyıda yapılaşma gözükürken 2015 tarihli ortofotoya göre ise içe doğruda yapılaşmanın arttı̆̆ anlaşılmaktadır.

\subsubsection{Arazi Kullanım Planlaması Konusunda Değerlendirme}

İskenderun Körfezi (Adana, Mersin, Hatay) Bütünleşik Kıyı Alanları Planı 644 sayılı Çevre ve Şehircilik Bakanlığı'nın Teşkilat ve Görevleri Hakkında Kanun Hükmünde Kararname'nin 7. maddesi uyarınca 08.10.2015 tarihinde onaylanmıştır. İskenderun Körfezi Bütünleşik Kıyı Alanları Planı'nın amacı; ülkemizin kıyı bölgelerinde kentleşme, sanayileşme, turizm ve ikinci konut gelişmesi gibi nedenlerle bir dizi sorunun bulunduğundan, ülkemizin kıyı alanları için bütünleşik bir planlama ve yönetim modelinin geliştirilmesi hedefiyle İskenderun Körfezi Kıyı Alanları için her tür ve ölçekteki arazi kullanım planları, sektörel planlar, projeler, uygulamalar, bunların izleme ve denetleme çalışmalarına esas olacak stratejilerin ve kararların geliştirilmesidir.

Dörtyol Erzin Planlama Bölgesi 5 alt bölgeye ayrılmıştır. 5A Bölgesinde Mevcut ve Planlı Tesisler İskele ve Deniz Terminalleri, Deniz İçi Boru Hatları, Limanlar, Dolgu Alanları, Gemi Bakım Onarım Tesisleri ve Gemi İnşa Sanayi Tesisleridir. Bölgede yer alması planlanan öncelikli tesisler ise Deniz içi Boru Hatları, İskeleler, Gemi Bakım Onarım tesisleri, Gemi inşa Sanayi tesisleri ve limanlardır.

Şekil 4'deki Hatay il Çevre Düzeni Planına göre çalışma bölgemiz olan Erzin İlçesi Turunçlu, Yeşilkent ve Dörtyol İlçesi Yeniyurt mahallerinindeki arazi kullanım planlaması gözükmektedir.

Turunçlu Mahallesi çevre düzeni planında Aşağıburnaz olarak gösterilmiştir. Buna göre kıyı şeridi içerideki arazi kulanım planında Serbest Bölge, Doğal karakteri korunacak alan, Sulak alan ve liman gibi kıyı tesisleri alanı planlanmıştır. 
Ayrıca bu mahallede birden çok boru hattı gösterimi de bulunmaktadir.

Yeşilkent Mahallesi'nde ise kıyı şeridi içerisinde sulak alan ve boru hattı gösterimi bulunmaktadır.
Yeniyurt Mahallesi çevre düzeni planında kıyı şeridi uzunluğu fazla olması sebebiyle arazi kullanım planlamasında daha çok çeşitlilik bulunmaktadır. Buna göre bu mahallenin planlamasında kentsel yerleşik alan, sulak alan, sanayi depolama alanı ve boru hattı gibi gösterimler mevcuttur

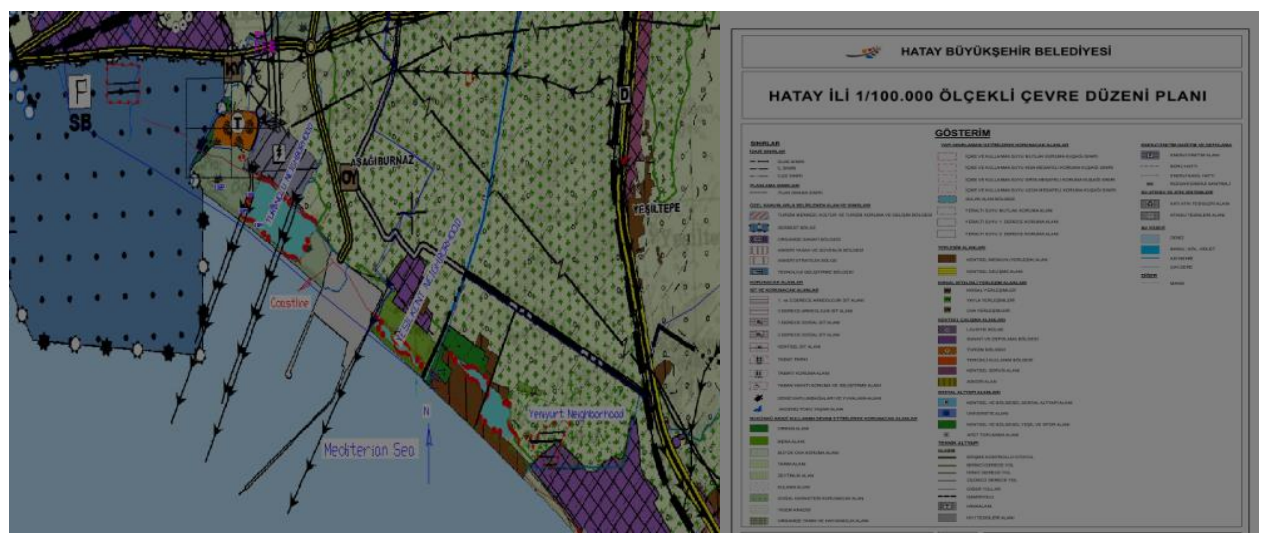

Şekil 4. Hatay il Çevre Düzeni Planı örneği ve lejantı

Yeniyurt Mahallesi'nde 1986 tarihinde mevzi planlar yapılarak onaylanmış ve yapılaşmanın önü açılmıştır. Mevzi planlar 1986 tarihinde belediye sınırları dışında il özel idaresi tarafından onaylanmıştır. Bu planlara göre kıyı bölgesinde tatil siteleri yapılmıştır.

\subsection{Mülkiyet Açısından İrdeleme}

\subsubsection{Turunçlu ve Yukarıburnaz Mahallesi İncelemesi}

Turunçlu (Yukarıburnaz Mahallesi) Mahallesi'nde kıyı kenar çizgisi sınırlarında kalan ve dava açılan 1003(596/17),1008(596/16),1022(596/20),1023(596/19),1024(5 96/18) nolu parseller bulunmaktadır. Çizelge de kıyı kenar çizgisinde kalan parseller numaraları, yüzölçümleri ve cinsi gözükmektedir.

Tablo 2. Turunçlu Mahallesi Kıyı-Kenar çizgisi ihlal miktarları

\begin{tabular}{|c|c|c|c|c|}
\hline Mahalle & Ada/Parsel No & $\begin{array}{c}\text { KKÇ İhlal } \\
\text { Miktarı } \\
\left(\mathbf{M}^{\mathbf{2}}\right)\end{array}$ & Type Of Property & Malik Bilgisi \\
\hline Turunçlu & $1003(596 / 17)$ & 449046,21 & Tarla & Davall \\
\hline Turunçlu & $1008(596 / 16)$ & 37609,37 & Arsa & Davall \\
\hline Turunçlu & $1022(596 / 20)$ & 332190,88 & Tarla & Davall \\
\hline Turunçlu & $1023(596 / 19)$ & 40120,62 & Tarla & Davall \\
\hline Turunçlu & $1024(596 / 18)$ & 444688,5 & Tarla & Yine \\
\hline
\end{tabular}

Şekil 5 de kıyı kenar çizgisi sınırlarında kalan dava süreci devam etmektedir. Yine 596 ada 20 parselin 1022(596/20), 1023(596/19), 1024(596/18) nolu parsellerin kuzeyinde ve batısında tescil dış1 alanlar mevcuttur. Bu alanların kadastral krokisi gözükmektedir. Buna göre parsellerin tamamı bir bölümü şahıslar tarafından işgal edilerek yazlık amaçlı derme kıyı kenar çizgisinde kalmaktadır. Parsellerin mülkiyet ilgili çatma barakalar yapılmaktadır

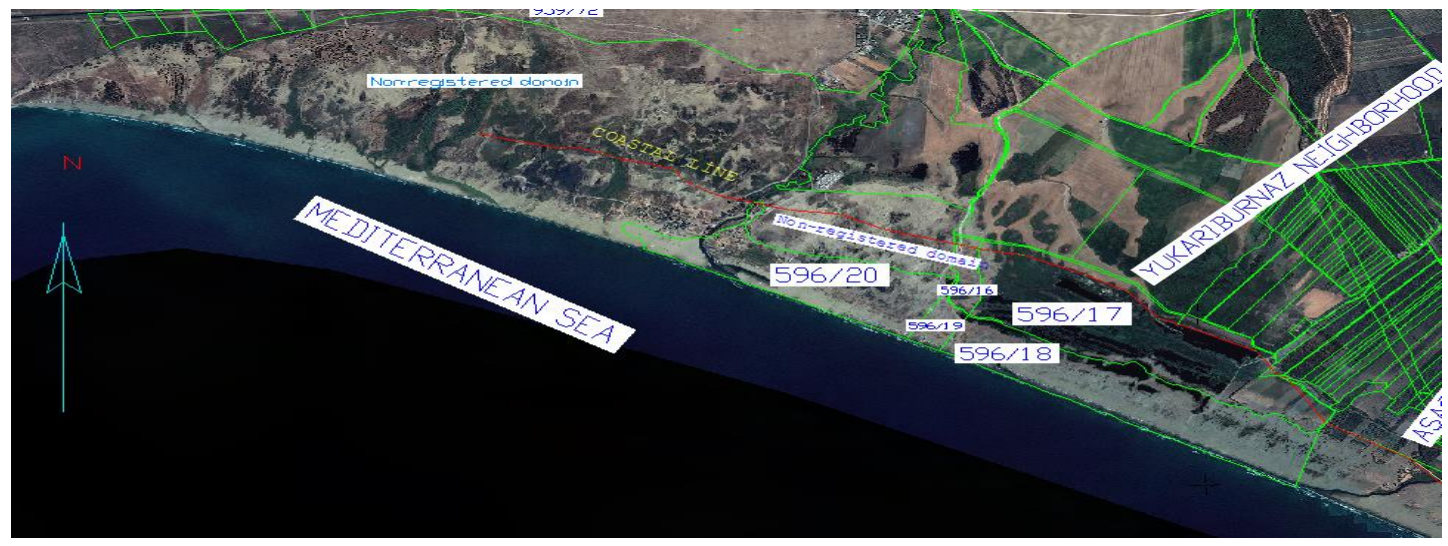

Şekil 5. Turunçlu (Yukarıburnaz) Mahallesi kıyı kenar çizgisi ihlal haritası, mülkiyet (yeşil) ve Kıyı kenar çizgisi (kırmızı). 


\subsubsection{Aşağıburnaz Mahallesi}

Aşağıburnaz (Yeşilkent) Mahallesi'nin haritasından da anlaşılacağı üzere kıyı şeridi $1250 \mathrm{~m}$ olup diğer iki mahalleye göre en kısa kıyı şeridine sahiptir. Kadastral anlamda kıyı kenar çizgisi içerinse sadece bir parsel kısmen kalmaktadır. 631ada 107 (9538eski parsel no) nolu parsel kısmen kıyı kenar çizgisi içerisinde kalmakta ve bu parsel üzerinde boru hattı mevcut olup, şekildeki haritada boru yaklaşma sınırı da gözükmektedir.

\subsubsection{Yeniyurt Mahallesi}

Yeniyurt Mahallesi idari sınır olarak Dörtyol İlçesi'ne bağlı olmasına rağmen mahallenin bir kısmı Erzin idari sınırlarında kalmaktadır.5500 metre kıyı şeridine sahip olup en fazla ihlal bu mahallede gözükmektedir. Aşağıdaki çizelgede kıyı kenar çizgisi ihlali yapan parseller ve ihlal miktarları belirtilmiştir. Tatil sitelerinin bulunduğu bu mahallede birçok yapı da kıyı kenar çizgisi içerisinde kalmıştır. Kenar çizgisi içinde kalan alanlar Netcad programıyla hesaplanmıştır.

Tablo 3. Yeniyurt Mahallesi Kıyı-Kenar çizgisi ihlal miktarları

\begin{tabular}{|c|c|c|c|c|c|c|c|c|}
\hline & $\begin{array}{c}\text { Parsel } \\
\text { No }\end{array}$ & $\begin{array}{c}\text { KKÇ } \\
\text { İhlal } \\
\text { Miktar } \\
\text { I(m2) }\end{array}$ & $\begin{array}{c}\text { Parsel } \\
\text { No }\end{array}$ & $\begin{array}{c}\text { KKÇ } \\
\text { İhlal } \\
\text { Miktar } \\
\text { l(m2) }\end{array}$ & $\begin{array}{c}\text { Parsel } \\
\text { No }\end{array}$ & $\begin{array}{c}\text { KKÇ } \\
\text { İhlal } \\
\text { Miktar } \\
\text { l(m2) }\end{array}$ & $\begin{array}{c}\text { Parsel } \\
\text { No }\end{array}$ & $\begin{array}{c}\text { KKÇ } \\
\text { İhlal } \\
\text { Miktar } \\
\text { I(m2) }\end{array}$ \\
\hline \multirow{23}{*}{ Yeniyurt } & 292 & 233 & 1375 & 1724 & 1869 & 48 & 1905 & 10192 \\
\hline & 330 & 650 & 1610 & 19 & 1870 & 27 & 1100 & 52989 \\
\hline & 331 & 803 & 1611 & 19 & 1878 & 83 & $140 / 5$ & 95 \\
\hline & 339 & 3292 & 1613 & 18 & 1879 & 51 & $140 / 6$ & 66 \\
\hline & 350 & 6682 & 1614 & 17 & 1665 & 99 & $141 / 5$ & 131 \\
\hline & 1096 & 77648 & 1615 & 18 & 1942 & 44 & $141 / 6$ & 114 \\
\hline & 1104 & 144600 & 1616 & 22 & 1947 & 48 & $142 / 5$ & 36 \\
\hline & 1505 & 31 & 1587 & 82 & 1948 & 39 & $142 / 6$ & 112 \\
\hline & 1506 & 35 & 1588 & 69 & 1949 & 36 & 290 & 117824 \\
\hline & 1507 & 37 & 1589 & 55 & 1957 & 66 & 2025 & 309 \\
\hline & 1508 & 42 & 1590 & 51 & 1958 & 56 & 2026 & 312 \\
\hline & 1509 & 47 & 1663 & 148 & 1959 & 55 & 2027 & 309 \\
\hline & 1515 & 29 & 1664 & 110 & 1924 & 30 & 2028 & 307 \\
\hline & 1516 & 31 & 1831 & 72 & 1925 & 25 & 2036 & 319 \\
\hline & 1578 & 17 & 1832 & 65 & 1926 & 20 & 2037 & 313 \\
\hline & 1579 & 14 & 1837 & 59 & 1927 & 17 & 2038 & 309 \\
\hline & 1580 & 13 & 1838 & 58 & 1928 & 17 & 2039 & 313 \\
\hline & 1581 & 12 & 1839 & 52 & 1968 & 78 & 2096 & 5427 \\
\hline & 1582 & 13 & 1840 & 45 & 1969 & 74 & 2097 & 143505 \\
\hline & 1597 & 21 & 1845 & 48 & 1970 & 73 & & \\
\hline & 1598 & 19 & 1846 & 37 & 2029 & 46 & & \\
\hline & 1599 & 19 & 1847 & 35 & 2278 & 853 & & \\
\hline & 1600 & 20 & 1848 & 31 & 2279 & 226 & & \\
\hline
\end{tabular}

\section{Bulgular ve Değerlendirme}

\subsection{Kıyı Bölgesindeki Zamansal Değişim Konusunda Değerlendirme}

Turunçlu (Yukarıburnaz) Mahallesi 596 ada 20 (1022eski parsel no) parselin tamamıma (332190.88m2) yakınının kıyı kenar çizgisi içinde kaldığı anlaşılmaktadır. Söz konusu parsel tarla vasıflı olup mülkiyeti dava konusudur. Ayrıca söz konusu parsel üzerinde kaçak yapılaşmalar gözükmektedir. Bu parselin batısındaki boş alan tescil dışı bırakılmıştır. Bu alanın ortasından da kıyı kenar çizgisi geçmektedir. Tescil harici ve mülkiyeti maliye hazinesine ait olan araziler işgal edilmekte ve derme çatma yapılarla bu bölgeler yazlık evler ve plaj olarak kullanılmaktadır.2018 yılında bu yapılar Hatay Büyük Şehir belediyesi tarafından yıkılmıştır.
Arazi kullanım planlaması değerlendirildiğinde (çevre düzeni planına göre) kıyı Turunçlu (Yukarıburnaz) Mahallesi kıyı şeridinde kalan 596 ada 20 (1022eski parsel no) nolu parselin bir kısmının serbest bölgede, bir kısmının ise doğal koruma alanı içerisinde kaldığı yine 596 ada 19 (1023 eski parsel no) nolu parselin boru hattı olarak gösterildiği, 596 ada 18 (1024 eski parsel no) nolu parselin sulak alan tanımlı gösterim ve boru hattı olarak gösterildiği anlaşılmaktadır. Yine 596 ada 16 (1008 eski parsel) no nolu parselin boru hattı ve (1003 eski parsel no) nolu parselin ile sulak alan olarak gösterilmiştir. Tescil harici olarak gözüken 596 ada 18 nolu parselin doğusundaki alan ise kıyı tesisi alanı olarak planlamıştır. Yine 596 ada 20 nolu parselin batısındaki tescil harici alanda serbest bölge olarak planlamıştır. 


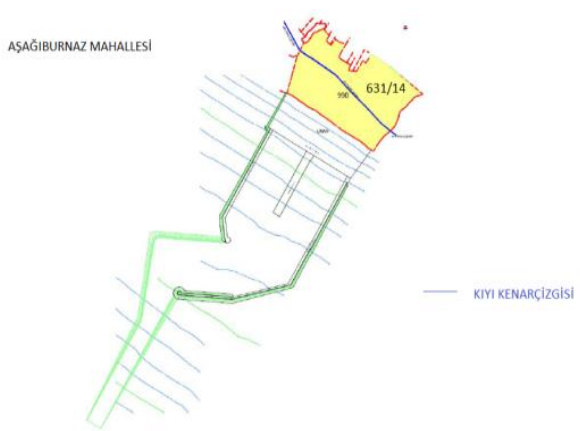

a)

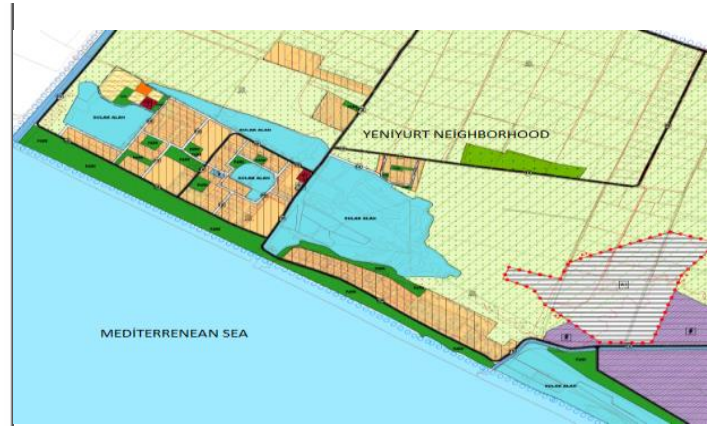

b)

Şekil 6. a) Aşağıburnaz Mahallesi 631 ada 14 nolu parselin plan örneği (Liman) (URL.6.) b) Yeniyurt Mahallesi (Dörtyol İlçesi) nazım planı 1/5000

Aşağıburnaz (Yeşilkent) Mahallesi kıyı şeridi uzunluğu kısa olduğu için iki parseli kapsamaktadır. 631ada 107 (9538 eski parsel no) nolu parselin arazi kullanım planlamasındaki gösterimi boru hattı ve sulak alandır. Yine 631 ada 14 nolu (Eski Turunçlu Mahallesi 990 nolu parsel) parselin arazi kullanım planlamasında "Liman alanı "olarak revize edilmiştir). "İskenderun Körfezi Kıyı Alanları Bütünleşik Planlama ve Yönetim Projesinin revizyonu niteliğinde olan "İskenderun Körfezi (Adana-Mersin-Hatay) Bütünleşik Kıyı Alanları Planı" Çevre ve Şehircilik Bakanlığı'nca 08.10.2015'te onaylanmıştır. Bu planda 631 ada 14 (eski 990) parselin yer aldığı DörtyolErzin Bölgesi 5A alt bölgesinde "liman yapılabilir" kararı getirilmiştir. Bayındırlık ve İskân Bakanlığınca 2010 yılında onaylanan İmar Planı ile planlama alanında getirilen "Liman, Tersane ve İskele" kullanım kararlarının "Liman Alanı "olarak revize edilmiş ve 35,93ha.' lık Liman Alanı ilavesini kapsamakta olup planlama alanı yaklaşık 116.60 ha'dır. (Şekil 6a)

Yeniyurt kıyı şeridi olarak en uzun sahile sahip mahalledir. Bu mahallede arazi kullanım planlamasına göre parsellerin çoğu yerleşim alanı olarak planlamıştır. Bölge de yoğun tatil siteleri yapılaşması mevcuttur. Kıyı kenar çizgisi bu bölgedeki mevcut yapılaşmayı kurtaracak şekilde geçirilmiş, yine planlama da şehirsel gelişmenin gerisinde geldiği için yapılaşmayı kurtaracak şekilde planlandığı düşünülmektedir. Bu mahallede bir kısım parselleri de enerji depolama alanı olarak planlanmıştır. Yeniyurt mahellsininde içine alan Hatay ili Dörtyol İlçesi 1/5000 ölçekli revize nazım imar planı Hatay Büyükşehir belediye meclisince 31.07.2019 tarih 160 sayılı kararla onaylanmıştır. (Şekil 6b). Yeniyurt Mahallesi 2014 yılı öncesi belde belediyesi sınırlarında kaldığından bölgede tatil sitelerinin yapılması amacıyla parsel bazlı mevzi imar planları yapılmış ve 1986 tarihinde Dörtyol İlçesi Yeşil Beldesi belediyesince onaylanmıştır.

\subsection{Kıyı Kenar Çizgisi ve Mülkiyet Açısından Değerlendirme}

Çalışma bölgesinde Toplam 12630 metre uzunluğa sahip çalışma alanının tamamının kıyı kenar çizgisi tespitleri yapıldığ Ayrıca, Kıyıda kalan ve tapu iptali gereken taşınmazlar içinde maliye hazinesi adına kayıtlı taşınmazların sayı olarak az olmasına karşın yüzölçüm oranı olarak \%58,17 ile ilk sırada yer aldığ1 görülmektedir. Bunun en önemli nedeni Yeşilkent Mahallesi'ndeki kıyı kenar çizgisi ihlali yapan tek taşınmaz olan 581231,68 m2 yüzölçümlü ve Mera vasfindaki 250578m2 si kıyı kenar çizgisinde kalan 631 ada 107 (9538 eski parsel no) parsel sayılı taşınmazla ilgilidir. (Tablo. 2).

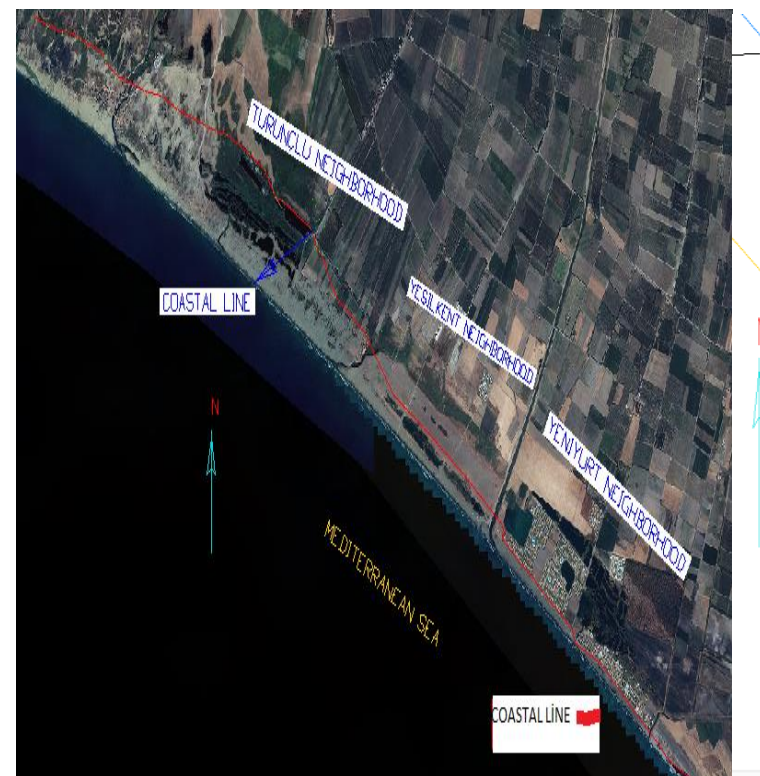

Şekil 7. a) Ortofoto haritada mahallelerdeki kıyı kenar çizgisi gözükmektedir. eden parseller gözükmektedir

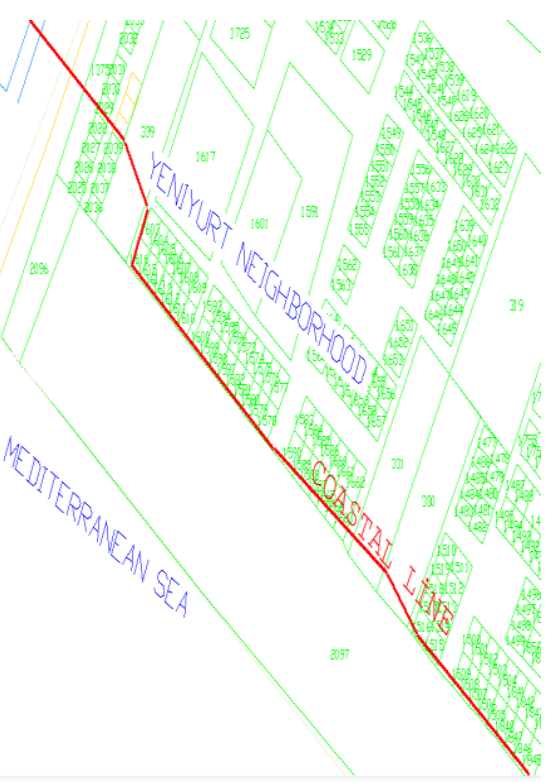

b) Yeniyurt Mahallesi'ndeki kıyı kenar çizgisini ihlal 
Çalışma alanının Yeniyurt Mahallesi sınırlarında toplam 77 adet parselin kıyı kenar çizgisi ihlali tespit edilmiştir. (Tablo 3)

Ayrıca söz konusu çalışma kapsamında ihlale konu parsellerin tapu kayıtlarının incelenmesi neticesinde Maliye Hazinesi adına kayıtlı 6 adet, şahıs ve şirket adına kayıtlı 80 adet ve kamu kuruluşları adına kayıtlı üç adet taşınmazın kıyı kenar çizgisi ihlali yaptığı anlaşılmıştır. (Tablo 2). Çalışma alanının Yeniyurt Mahallesi sınırlarında toplam 77 adet parselin kıyı kenar çizgisi ihlali tespit edilmiş olup bu parsellerin toplam $303008 \mathrm{~m} 2$ ihlal ile çalışma bölgesinde en fazla ihlal yapılan kısım olduğu görülmüştür. (Tablo 3)

Çalışma alanında kamu kurumu ve maliye hazinesi adına kayıtlı toplam 1.692.793m2 yüzölçümlü taşınmazlar ile 350 parselde $559296 \mathrm{~m} 2$ alana sahip Mülkiyeti Tarım işletmeleri Genel Müdürlüğüne ait okaliptüs ormanı, Ayrıca 2096 parselde $3877 \mathrm{~m} 2$ Maliye Hazinesi adına kayıtlı Kanal ile 2279 parselde 999,59 m2 Devlet Su İşleri Genel Müdürlüğüne ait 1 Adet Kanal vasfında taşınmaz bulunmaktadır.

Kıyı Kenar çizgisi mülkiyet ilişkisi incelenirken üzerinde durulması gereken önemli bir ayrıntı da parseller üzerinde inşa edilen yapıların kıyı kenar çizgisi ile ilişkileridir. Şekilde görüldüğü gibi kıyı kenar çizgisi yapılaşmadan sonra geçtiği için yapılaşmanın olduğu yerlerde denize doğru keskin kırıklar oluşturmakta ve mesafe azalmaktadır. Yapılaşmanın olduğu yerlerde denize olan mesafe $100 \mathrm{~m}$ 'nin altına düşmekte diğer yerlerde ise $200 \mathrm{~m}$ civarındadır. Bu kapsamda çalışma bölgesinin; Yeniyurt Mahallesi'nde 49 adet Dubleks Bina vasfinda şahıslara ait toplam 29173,56 m2 yapı taşması ve 25 Adet Arsa niteliğinde şahıslara ait Toplam 8689,33 m2 kıyı kenar çizgisi ihlali yapan taşınmaz tespit edilmiş olup bu parsellerin toplam 303008m2 ihlal ile çalışma bölgesinde en fazla ihlal yapılan kısım olduğu belirlenmiştir edilmiştir. Turunçlu Mahallesi Burnaz mevkiinde Kıyı kenar çizgisinde kalan 1.303.653 m2 yüzölçümlü Tarla vasfinda 5 Adet mülkiyeti kesinleşmemiş davalı taşınmaz mevcut olup bu taşınmazlar üzerinde 2011 ve 2016 yıllarında tesis edilmiş Türkiye petrolleri Anonim ortaklığı ve DSİ lehine irtifak hakkı kurulmuş kamulaştırma şerhleri mevcuttur. Turunçlu Mahallesi'nde Kıyı kenar çizgisinde yapılaşma tespit edilmemiştir. Aşağıburnaz (Eski Yeşilkent) Mahallesi'nde ise maliye hazinesi adına kayıtlı mera vasfinda $250578 \mathrm{~m} 2$ si kıyı kenar çizgisinde kalan 1 adet taşınmaz ve onun batısında tescil harici alan bulunmaktadır. Aşağıburnaz Mahallesi'nde kıyı kenar çizgisinde yapılaşmanın olmadı̆̆

\section{Sonuç ve Öneriler:}

İncelediğimiz Hatay ili Erzin İlçesi Yukarıburnaz, Aşağıburnaz, Turunçlu mahalleleri ile Dörtyol İlçesi Yeniyurt Mahallesi'nde 1975 ,2011 tarihli hava fotoğrafları ve 2015 yılın ait ortofotodan anlaşılacağı üzere yapılaşmanın arttığ1 yazlık amaçlı konutların özellikle Yeniyurt Mahallesi'nde yoğunlaştığı görülmüştür.

Kıyı kenar çizgisi bakımından değerlendirildiğinde kıyı kenar çizgisi çalışmalarının tamamlandığı ancak arazideki değişime göre geç kalındığı görülmektedir. Yapılaşmalar nedeniyle kıyı kenar çizgisi bu bölgelerde denize daha yakın geçirildiği belirlenmiştir. Kıyı kenar çizgisinin mülkiyeti kestiği kıyı bölgesine taşan yapılar ve parsellere dava açıldığı belirlenmiştir. Hazineye ait parsellerin kıyı bölgesinde kalan bölümlerinin tescilinin iptal edilmesi ve özel şahıslara ait taşınmazların kamulaştırılması gerekmektedir.

Kıyı bölgesinde özellikle son 30 yılda bölgenin idari yapında sürekli değişim yaşanması nedeniyle arazi planlaması konusunda farklı uygulamalara sebep olmuştur. İl özel idaresinden belde belediyesine, ilçe belediyesinden büyükşehir belediyesi yetki alanına giren bölge arazi kullanım planlama yetkisi son olarak çevre ve şehircilik bakanlığının bütünleşik kıyı planlaması yetkisi içerisinde kalmaktadır. Bölgenin petrol ve doğalgaz boru hatları nedeniyle enerji bölgesi olması, demirçelik sanayi ve organize sanayi bölgelerine olan yakınlık dolayısıyla liman ve iskele taleplerini artırmaktadır. Etrafındaki şehirlerin yazlık konut ve plaj talepleri nedeniyle yapılaşmaya sebep olmaktadır. Kıyı bölgesi son 30 yılda gerek idare yapıdaki yetki karmaşası ve gerekse de planlama ve kıyı kenar çizgisi çalışmalarındaki gecikmeler nedeniyle deformasyona uğramaya devam etmektedir.

\section{Kaynakça}

Akbulak, C., Erginal, A., Gönüz, A., Öztürk, B., \& Çavuş, Z. (2008). Investigation Of Land Use And Coastline Changes On The Kepez Delta Using Remote Sensing. Black Sea/Mediterranean Environment, 14(2), 95-106.

Aydın, M., \& Uysal, M. (2013). Kıyı Çizgisi Değişiminin Uydu Görüntüleri Yardımıyla İzlenmesi: Sakarya-Karasu. Harita Teknolojileri Elektronik Dergisi, 5(3), 24-32.

Aykut, N.O., Doğan U., Ata, E.,Arı, A. (2005).. Gps İle Kıyı Çizgisinin Belirlenmesi, Karaburun Örneği. Harita ve Kadastro Mühendisleri Odası, Mühendislik Ölçmeleri STB Komisyonu 2. Mühendislik Ölçmeleri Sempozyumu 23-25 Kasim 2005, İTÜ - İstanbul

Chang, Y., Chu, K.-W., \& Chuang, L. Z.-H. (2018). Sustainable Coastal Zone Planning Based On Historical Coastline Changes: A Model From Case Study In Tainan, Taiwan. Landscape And Urban Planning, 174, 24-32.

Çay,T.. - Nacar,F.(2016)" Region Coastal Land Management And Tracking Changes In Ownership Status" „ICEESD 2016 : 18th International Conference On Ecosystems, Environment And Sustainable Development, January 26 27, 2016,Jeddah, Saudi Arabia

Gens, R. (2010). Remote Sensing Of Coastlines: Detection, Extraction And Monitoring. International Journal Of Remote Sensing, 31(7), 1819-1836.

Ghosh, M. K., Kumar, L., \& Roy, C. (2015). Monitoring The Coastline Change Of Hatiya Island In Bangladesh Using Remote Sensing Techniques. ISPRS Journal Of Photogrammetry And Remote Sensing, 101, 137-144.

Kiraci, A. C., Işcan, L., Eker, O., Yilmaz, A., Özerbil, T., Maraş, H. H., Firat, O., \& Akabali, O. A. (2010). Sayisal Hava Kamerası ve Fotogrametriye Kazandırdıkları.Harita Dergisi ,Ocak 2010 sayı :143,26-32

Li, R., Di, K., \& Ma, R. (2001). A Comparative Study Of Shoreline Mapping Techniques. GIS For Coastal Zone Management, 53-60. 
Öztürk, D. (2013). Hücresel Otomat-Markov Zinciri Yöntemiyle Samsun Kıyı Alanlarındaki Mekansal Değişimlerin Modellenmesi. TMMOB Harita Ve Kadastro Mühendisleri Odas1, 14, 14-17.

Sesli, F.A., Akyol, N., İnan, H.İ., 2002. Coğrafi bilgi sistemleri ile kıyı kenar çizgisi-mülkiyet ilişkilerinin incelenmesi, Türkiye Sekizinci Esri ve Erdas Kullanıcıları Grubu Toplantıs1, 6-7 Haziran 2002, ODTÜ, Ankara, www.avesis.erciyes.edu.tr.

Supriyono, S. (2018). Critical Land Detection Watershed River Bengkulu And Effect Of Coastal Area Using Geographic Information System. Sumatra Journal Of Disaster, Geography And Geography Education, 2(1), 30-37.

URL1. Retrieved 10.02 .2021

From
URL2. Retrieved 15.03.2019 From Https://Www.Tuik.Gov.Tr/

URL3. $\quad$ Retrieved 3.01.2021 From Http://Www.Hatay.Gov.Tr/Sosyal-Ve-Cografi-Durum

URL4. $\quad$ Retrieved 18.03.2021 From Https://Mpgm.Csb.Gov.Tr/Kiyi-Alanlarinin-Onemi-I-84350

URL5. $\quad$ Retrieved 12.03.2021 From Https://Www.Dortyoltso.Org.Tr/Img/Document/IlcemizSosyo-Ekonomik-Raporu.Pdf

Ünel, F. B., Çelik, M. Ö., Yakar, M., \& Kuşak, L.(2019). Kiyi Yönetimi İçin Kiyi Ve Kiyi Kenar Çizgisinin Belirlenerek Mersin Kiyi Bilgi Sistemi Altyapisinin Araştirilmasi.

Valeyev, A., Karatayev, M., Abitbayeva, A., Uxukbayeva, S., Bektursynova, A., \& Sharapkhanova, Z. (2019). Monitoring Coastline Dynamics Of Alakol Lake In Kazakhstan Using Remote Sensing Data. Geosciences, 9(9), 404. 